\title{
METHODOLOGY FOR THE EVALUATION OF SCHOOL ZONES IN A DRIVER SIMULATOR
}

\author{
Didier Valdés-Diaz, PhD, Benjamín Colucci, PhD, Maria Xelena Rojas, BS, Enid Colón, BS and \\ Ricardo García, BS \\ University of Puerto Rico at Mayaguez \\ didier.valdes@upr.edu, benjamin.colucci1@upr.edu,maria.rojas7@upr.edu, enid.colon1@upr.edu and \\ ricardo.garcia5@upr.edu
}

\begin{abstract}
Traffic crashes involving school-age children are a serious safety concern, as there has been an increase in the number of school-age pedestrians and cyclists being injured and killed throughout the years. This study aims to investigate the effect of different countermeasures on driver behavior while driving in and around school zones. Initially, a detailed screening process to select the school zones was performed based on Road Safety Audit, Highway Safety Manual and Engineering Judgement basis. The selected school zones were then studied in detail to generate their scenarios and define the appropriate variables. New signage and pavement marking configuration will be tested via experimentation leveraging the UPRM driving simulator. It is expected that the proposed changes in signage, pavement marking and the incorporation of new devices of traffic control will significantly improve the safety and operational parameters for the school zones studied.
\end{abstract}

Keywords-School zone, Safety, Countermeasures, Speed, Driver behavior.

\section{INTRODUCTION}

A report on the global situation of road safety delivered by the World Health Organization (OMS) in 2009, indicates an increase in traffic accident injuries from the ninth cause of mortality in 2004 to the fifth in 2030. This estimation is becoming a reality, as accident rates are increasing in most countries of the world over the years [1].

Several countries have developed and implemented traffic safety campaigns to mitigate all these increments in crashes and fatalities. A press release from the InterAmerican Development Bank (IADB) mentioned initiatives by Latin American and Caribbean countries that have had a positive impact in crash reduction. The "Yellow May Movement" developed in Brazil to create awareness to the high level of crash related fatalities and injuries was recognized as a succesful experience by IADB. Also, the improvements made in the system to grant driving licenses in Chile and the development of a guide for the analysis and design of roadways in Costa Rica were outstanding [2].

However, statistics from the Safe Kids Worldwide organization show that there has been an increase in $13 \%$ in pedestrians' death rate of young people 12-19 years old, in the period of 2013 to 2015 . A total of 284 teens of this age range were killed while walking in 2015 [3]. According to the annual report of Traffic Safety Facts of 2015 published by the
National Highway Traffic Safety Administration (NHTSA) [4], in the United States this year 5,376 pedestrians were killed and 70,000 were injured after being involved in a traffic crash. With respect to cyclist, it is reported that 818 were killed and 45,000 were injured. Of these data, the $4.8 \%$ of the pedestrians killed, $12.8 \%$ of pedestrians injured, $6.11 \%$ of cyclist killed and $15.6 \%$ of the cyclist injured correspond to children under the age of 16 years.

In 2018, Puerto Rico has seen very high numbers of pedestrian fatalities. In so far this year, 20 pedestrians and 2 cyclists have been killed in crashes. These are seven additional pedestrians compared to the 13 that died in 2017. These numbers generate a lot of concern for vulnerable users of the highway system [5]. In and around school zones, safety is greatly affected by speeding and its combination with deficiencies in signage. Article 5.02 of Law 22, "Puerto Rico Vehicles and Traffic Law" approved in 2000, states that school zones in rural areas must have a speed limit of $25 \mathrm{mph}$, while school zones in urban areas must have a speed limit of $15 \mathrm{mph}$ [6]. However, these speed limits are rarely followed as stated.

Two research questions will be at the center of this study 1) Which is a suitable methodology to select school zones to study? 2) What are the best countermeasures to maximize drivers' speed limit compliance within school zones? These research questions are related to Federal initiatives aimed at achieving a significant reduction in traffic fatalities and serious injuries on all public roads with an emphasis in the issue of school-age children's traffic safety.

\section{LITERATURE REVIEW}

In the event of a crash, vehicles are designed to protect their passengers from injury while pedestrians, cyclists, and motorists are referred to as vulnerable road users due to the risk they face against traffic. Some of these users are more vulnerable than others, such as older ad, persons with disabilities, and children.

A variety of roadway characteristics and human factors affect the occurrence of crashes. Different agencies are creating guidelines, manuals and campaigns to emphasize the importance of including the safety in roadway evaluation and design. Not only to consider vehicle users but also to include 
pedestrians and cyclist. In fact, the development of the complete street concept and the adoption of complete street laws in Puerto Rico and the U.S. recognizes that streets must be designed for users of all ages and abilities despite their mode of transportation.

School zones are the focus of the research project reported in this paper. Tipically, high number of school children and young pedestrians cross the surrounding school streets and walk or bike to reach their schools. The number of children involved in traffic crashes reported by NHTSA [1] confirm the importance of improving traffic safety in and around school zones. This study is aimed to look for strategies to tackle this problem. The initial activity performed in this study was to select school zones that represent typical but also critical conditions. The basis for the school selection process included the fundamentals presented by the Highway Safety Manual, the procedures developed for Road Safety Audits and the engineering judgment as defined in the MUTCD.

The Highway Safety Manual is a resource that provides information and methodologies to support the decision making process based on safety aspects [7]. Network Screening is a section of this manual that provides guidance to identify potential study sites for the application of countermeasures, that can reduce the crash rate. The screening consist of 5 steps: establish focus, identify network and establish reference populations, select performance measures, select screening method, and screen and evaluate results.

Steps 1 and 2 refer to the definition of either a site or a type of crash that wants to be evaluated. Step 3, helps determine the performance measure to be implemented by considering crash data availability, traffic volume, and roadway characteristics. Step 4, defines if the places to be evaluate correspond to segments, nodes or a combination of both in addition to the screening method to use considering the performance measure of step 3. At the end of the process, the results show an orderly list of sites that are most likely to have a reduction on crashes with the implementation of a countermeasure.

Another mechanism for the analysis of safety of on existing or future roads are the Road Safety Audits (RSA). RSA are defined as an examination of roads to determine if there are improvements that could be made in safety [8]. The team to perform a RSA must be multidisciplinary, independent from the engineer who design the road. RSA include field observations, audit analysis and presentation of project reports with findings.

The knowledge and criteria of each engineer complement and interpret data, reports, previous analysis, the information provided by different agencies, books and reports comes to play. This is known as the application of engineering judgment. The Manual on Uniform Traffic Control Devices (MUTCD) defines the engineering judgment as decisions made by engineers based on pertinent information given in different manual and sources to appropriately design and implement traffic control devices [9].

The following sections of this paper state the problem of interest and the methodology followed to select the school zones that will be used to test new highway safety strategies. At the end, the methodology devised to test these strategies is presented followed by conclusions related to this study.

\section{PROBLEM STATEMENT}

In Puerto Rico there are a total of 1128 K-12 public schools. In western Puerto Rico there are a total of 159 public schools, corresponding to $15 \%$ of the total. In 2016, two speed studies were carried out in school zones in this area.

One of the studies was developed by Gonzalez [10], that suggested measures to improve safety in school zones in the western area of Puerto Rico. The speeds of 13 schools were evaluated. In addition, speed studies were conducted in others 6 schools in the same area [11]. Table 1 presents the results of the speed studies performed in the surroundings of the school zones presented.

\begin{tabular}{|c|c|c|c|c|c|}
\hline No. & Schools & Municipality & $\begin{array}{l}\text { Speed } \\
\text { Limit } \\
\text { (mph) }\end{array}$ & $\begin{array}{c}\text { Average } \\
\text { Speed } \\
\text { (mph) }\end{array}$ & $\begin{array}{c}\text { 85th } \\
\text { Percentile } \\
\text { (mph) }\end{array}$ \\
\hline 1 & Casa del Joven & Añasco & 15 & 25.9 & 29.0 \\
\hline 2 & Luis Muñoz Marin & Añasco & 15 & 21.55 & 27.0 \\
\hline 3 & Charles T. Irizarry & Mayagüez & 15 & 25.8 & 30.0 \\
\hline 4 & Elemental Miradero II & Mayagüez & 25 & 22.6 & 28.0 \\
\hline 5 & S.U. Samuel Adams & Aguadilla & 25 & 25.6 & 30.9 \\
\hline 6 & Jorge Seda Crespo & Rincón & 25 & 21.7 & 26.1 \\
\hline 7 & Aurea E. Quiles High & Mayagüez & 25 & 22.2 & 29.0 \\
\hline 8 & Teresita Nazario Middle & Mayagüez & 25 & 20.2 & 25.0 \\
\hline 9 & $\begin{array}{c}\text { James Garfield } \\
\text { Elemental }\end{array}$ & Cabo Rojo & 15 & 26.1 & 33.2 \\
\hline 10 & $\begin{array}{l}\text { Monserrate León de } \\
\text { Irizarry High }\end{array}$ & Cabo Rojo & 15 & 20.9 & 25.0 \\
\hline 11 & $\begin{array}{c}\text { Severo E. Colberg } \\
\text { Ramirez }\end{array}$ & Cabo Rojo & 15 & 20.7 & 27.0 \\
\hline 12 & S.U. Mildred Arroyo & Cabo Rojo & 15 & 27.9 & 35.0 \\
\hline 13 & Rafael Martinez Nadal & Mayagüez & 15 & 24.5 & 31.0 \\
\hline 14 & Octavio Cumpiano Font & Rincón & 25 & 28.3 & 30.8 \\
\hline 15 & Conrado Rodríguez & Rincón & 25 & 24.7 & 28.7 \\
\hline 16 & Dr. Carlos González & Aguada & 15 & 24.7 & 28.5 \\
\hline 17 & $\begin{array}{c}\text { Escuela Juana Rosario } \\
\text { Carrero }\end{array}$ & Aguada & 15 & 25.1 & 28.9 \\
\hline 18 & $\begin{array}{c}\text { Secondary Eladio } \\
\text { Tirado Lopez }\end{array}$ & Aguada & 25 & 19.9 & 23.5 \\
\hline 19 & María D. Faría & Mayagüez & 25 & 30.5 & 37.2 \\
\hline
\end{tabular}

Considering the speeds stipulated in article 5.02 of Law 22 , the results of these studies showed that in $68 \%$ of the school zones the average speed was higher than the posted speed limit and that in $89 \%$ of the school zones the 85 th percentile of the speed was higher than the posted speed limit.

Gonzalez [10], also conducted surveys to determine the drivers knowledge related to regulations and signage in 
school zones. Puerto Rican drivers 16 years old and above participated in the survey. One of the questions that were asked was: Do you know the speed in school zone varies depending if the school is located in a rural or urban area? also the participants were asked about the meaning of signs that are used in school zones and to mention how they recognize these areas.

Looking at results obtained from the data collected in the surveys, more than $60 \%$ of the people indicated that they have no knowledge of the speeds to which drivers must drive in school zones, whether rural or urban. Also, there are people who do not know the difference between pedestrian crossing signs and proximity to a school zone. Finally, is was observed that $52 \%$ of the participants identify the school zones by the pavement marking. In Puerto Rico pavement marking in school zone include a yellow line and due to the lack of maintenance in some cases they are in poor condition.

Considering the information presented above, problems related to excessive speed of vehicles and awareness of proximity to school zones are observed. Therefore, different combinations of signage and pavement markings will be tested to verify if there is a significant improvement in drives' compliance to posted speeds around school zones. It will also be tested if the new settings will improve the recognition of school zones around Puerto Rico.

\section{SCHOOL SELECTION METHODOLOGY}

Four primary steps were followed during the school selection process: (1) Evaluation of crash history, (2) Screening process, (3) Site selection, and (4) interviews. A brief description of each step follows.

\section{Evaluation of crash history.}

A review of the crash history of school zones in western Puerto Rico was carried out, making use of the Crash Analysis Reporting Environment database (CARE) made available by the Puerto Rico Department of Transportation and Public Works (PRDTPW). Variables like crash type, collision type, vulnerable users related, day of week and roadway characteristics were considered in this section.

\section{Screening process.}

The screening process was performed based on a combination of fundaments from the Highway Safety Manual and the application of Engineering Judgement. The focus and reference populations were established since the beginning of the research: school zones with the potential to reduce the numbers of crashes. The information of crashes by type and total numbers, and the information of the roadway and traffic volume for the schools studied were considered and combine in performance measures such as crash rates to characterize each of the school zones and obtain a ranked list of alternative selections.
A simple ranking method was used ordering schools with crash rate from high to low. At the end this ranking was evaluated using the engineering judgment and complemented with Google maps and streets views to better understand the surroundings of the schools and the environment in which these crashes happened.

\section{Site inspections.}

Applying concepts from Road Safety Audits, site inspections were carried out at the schools that passed the screening process. General information was gathered for each school including characteristics related to the signage around the school area, pavement markings and sidewalks, the students drop- off/pick-up dynamics, roadways geometry, faculty parking availability, and pavement condition, among others.

\section{Interviews.}

Interviews to school directors, teachers, parents and road users were conducted. These interviews included questions related to their perception of safety in the school zones, the condition of the roadway infrastructure and speeds that drivers used to travel through this area. There were also questions about the modes of transportation used by students to get to school and the aspects that could be changed to improve the safety around the school zones.

\section{PRIMARY AND SECONDARY INFORMATION ANALYSIS OF SCHOOL ZONES IN WESTERN PUERTO RICO.}

Secondary data was obtained for all the schools initially studied in the western region of Puerto Rico. The crash history with information from 2014 to 2016, AADT, maps, and results from previous speed spot studies. An initial screening was implemented with this data, where the schools that reported a small number or no crashes were removed. Primary information included primarily site visits and interviews in those schools remaining after the intial screening process was conducted. Using all the information, a more in-depth analysis was carried out. This analysis used a ranking of variables related to the exposure, the crash rate, the complexity of the environment and the interviews to the schools.

The exposure was measured by the volume of vehicles and specifically evaluating the Annual Average Daily Traffic (AADT) corresponding to the roadway in front of the school zones. The crash rate was calculated using the severity index and the AADT. Severity index refers to a measure that summarizes the types of crashes assigning a weight scale to each one of them according to their severity. A typical distribution assigns a weight of 12 to fatalities, 3 to personal injury and 1 to property damage only [12]. The crash rate was calculated as the rate of the weighted average of crashes related to $10,000 \mathrm{veh} /$ day. Table 2 presents the data corresponding to crashes differentiated by type, the calculated severity index, the AADT and the crash rate. 


\begin{tabular}{|c|c|c|c|c|c|c|}
\hline \multirow[b]{2}{*}{ School } & \multicolumn{3}{|c|}{ Crash Type } & \multirow[b]{2}{*}{$\begin{array}{l}\text { Severity } \\
\text { Index }\end{array}$} & \multirow[b]{2}{*}{ AADT } & \multirow{2}{*}{$\begin{array}{c}\text { Crash } \\
\text { Rate (per } \\
10,000 \\
\text { vpd) }\end{array}$} \\
\hline & $\begin{array}{c}\text { Property } \\
\text { Damage }\end{array}$ & Injury & Fatal & & & \\
\hline Rafael Martinez Nadal & 102 & 15 & 0 & 147 & 10306 & 143 \\
\hline Maria D. Faria & 37 & 8 & 1 & 73 & 21229 & 34 \\
\hline S.U. Samuel Adams & 26 & 6 & 0 & 44 & 42947 & 10 \\
\hline Conrado Rodriguez & 36 & 11 & 0 & 69 & 26674 & 26 \\
\hline S.U. Mildred Arroyo & 15 & 6 & 1 & 45 & 5824 & 77 \\
\hline Eladio Tirado Lopez & 16 & 5 & 0 & 31 & 8570 & 36 \\
\hline Franklin D. Rooselvelt & 215 & 54 & 2 & 401 & 77314 & 52 \\
\hline
\end{tabular}

Table 2: Safety and exposure data

The complexity of the environment refers to the information that was gathered from various sources including site inspections and virtual tours using Google Maps Street View ${ }^{\circledR}$. The interviews were ranked considering the information provided. Schools that reflected the greater sense of safety for their school community were ranked higher. Table 3 presents the ranking assigned by the research team to each one of the variables considered for the selection process. The final score is calculated as a sum of the rankings for all the variables. The two schools selected for further studied are the ones with the two lower scores: Franklin D. Roosevelt and S.U. Samuel Adams.

\begin{tabular}{|c|c|c|c|c|c|}
\hline Schools & Exposure & $\begin{array}{c}\text { Crash } \\
\text { Rate }\end{array}$ & $\begin{array}{c}\text { Environment } \\
\text { Complexity }\end{array}$ & Interviews & Total \\
\hline Rafael Martinez Nadal & 5 & 1 & 5 & 5 & 16 \\
\hline Maria D. Faria & 4 & 5 & 6 & 3 & 18 \\
\hline S.U. Samuel Adams & 2 & 7 & 1 & 1 & 11 \\
\hline Conrado Rodriguez & 3 & 6 & 4 & 6 & 19 \\
\hline S.U. Mildred Arroyo & 7 & 2 & 7 & 7 & 23 \\
\hline Eladio Tirado Lopez & 6 & 4 & 3 & 4 & 17 \\
\hline Franklin D. Rooselvelt & 1 & 3 & 2 & 2 & 8 \\
\hline
\end{tabular}

Table 3: Total Ranking

\section{DESCRIPTION OF SCHOOL ZONES SELECTED}

Two schools were selected, to carry out a more in-depth study. The Franklin D. Roosevelt and the Second Unit Samuel Adams.

The school Franklin D. Roosevelt is located in the municipality of Mayaguez, in an area classified as urban. Provides a level of education from Kinder to $6^{\text {th }}$ grade and has a student enrollment of 165 children. Figure 1 shows a view of the area where the school is located, marking with a square the school and with an oval a pedestrian bridge.

This school serves two communities that are separated by the arterial street PR-2. This six-lane arterial highway has a posted speed of limit $40 \mathrm{mph}$. Near the school, there is a pedestrian bridge with no ramps and the nearest signalized intersection to this bridge is located approximately a quarter of a mile away. The entrance to the school is in the Dr. Vadi Street, which is parallel to PR-2.

The site inspection conducted in this school showed that the signage and the pavement markings related to the school zone is deficient. Also, findings of the interviews indicate that some children are cared for by elderly people and by mothers who have babies and use strollers. Therefore, it is very difficult for them to use the pedestrian bridge. These people must go to the intersection, then cross the PR-2 which in this part has $812 \mathrm{ft}$-lanes to accommodate through and left turn lanes, walk to the school and use the same long route back home. In some cases, people cross under the bridge due to the long distance they must walk.

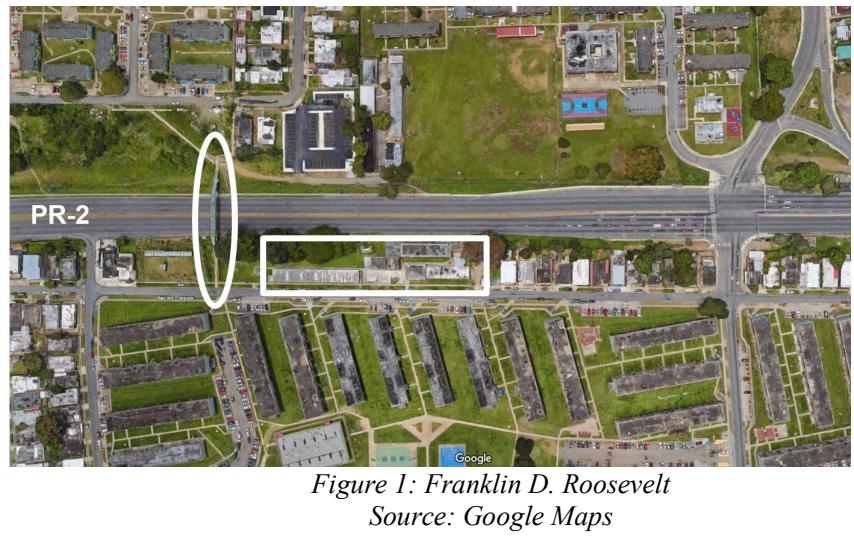

The second school selected is the Second Unit Samuel Adams, that is located in the municipality of Aguadilla, in an area is classifies as rural. provides a level of education from Pre-Kinder to $9^{\text {th }}$ grade and has a student enrollment of 900 children. Figure 2 shows a view of the area where the school is located, marking with a square the school and with an oval a pedestrian bridge.

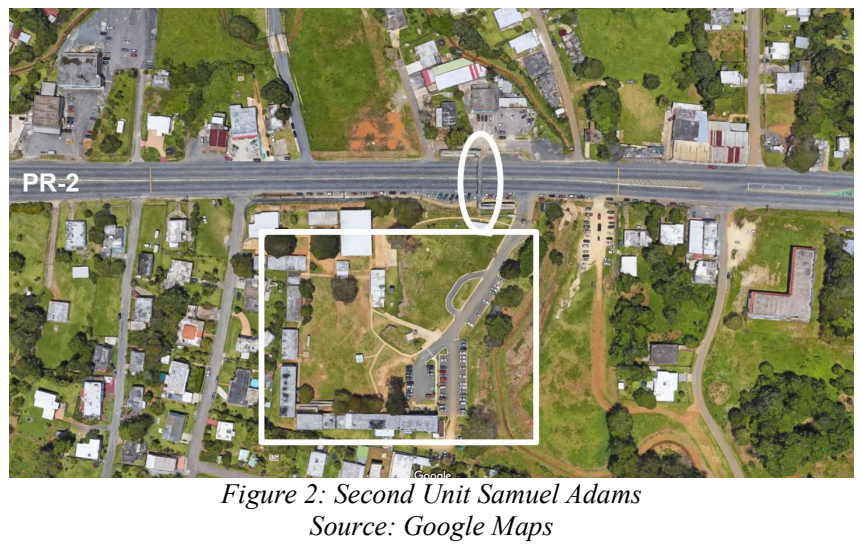

This school has direct access from the arterial highway PR-2. In this section, this highway has 3 lanes per direction and a posted speed limit of $45 \mathrm{mph}$. As it was mentioned before, this is a rural area, and there are some segments without sidewalks. There is a pedestrian bridge with ramps in front of the school to communicate the school with its surrounding area. Also, the two directions of the PR2 are separated by a New Jersey barrier that has a 5 -ft tall fence on top to eliminate the possibility for pedestrians to cross the street in that point, forcing them to use the bridge.

Inside the school, there is a drop-off area that is not used as expected. According to the interviews, the designated drop-off area is not convenient for parents with small children 
because they have to walk their child to the classroom. Therefore, parents park their cars on the shoulder of PR-2.

The findings of the site inspection showed that currently the speed limit and school zone signs have not been updated to the colors indicated in the last version of the MUTCD. Also, it was found that there are lines to delimit the beginning and end of the school zone, but there is no pavement marking with the word "School".

Furthermore, the main problem found in this school zone is the long line of vehicles that is formed by parents waiting to drop-off or pick-up their children. In addition, once the child is inside the vehicle, each driver must maneuver reversing onto the right lane of the arterial street or unexpectedly merge onto the arterial from the shoulder. All these maneuvers create additional congestion and deteriorate the safety for all the users.

\section{RESEARCH METHODOLOGY}

The methodology presented in this paper was developed for the evaluation of the different countermeasures to improve speed limit adherence and safety in and around school zones. The methodology is composed of the tasks that follow.

\section{Task 1: Literature Review}

A literature review is carried out, to identify various problems related to crashes and safety around school zones in different parts of the world and Puerto Rico. Countermeasures to improve the safety in school zones are also studied. Particularly, countermeasures that may have a significant effect on reducing the speed selected by drivers around school zones at least to comply with the established speed limits.

\section{Task 2: School Selection Process}

The steps previously mentioned in section IV (School Selection Methodology) are implemented. In this application of the methodology, two schools were selected to perform a deeper analysis considering that they have a great potential to improve safety in and around the school zones.

\section{Task 3: Base Scenario Development}

A base scenario is developed for each school. These base scenarios are created by replicating the characteristics of the school zones to resemble the current condition, using tools and software such as Google Maps ${ }^{\circledR}$, AutoCAD ${ }^{\circledR}$, SketchUp ${ }^{\circledR}$, Blender ${ }^{\circledR}$ and ISA ${ }^{\circledR}$. Initially, images are taken from Google Maps as a base to draw details in AutoCAD, including lines corresponding to lanes, pavement markings, and medians, among others. Then, this plan is processed with SketchUp where the 3-D environment is formally defined with the corresponding textures, color, and elevations; additional elements such as walls and bridges can also be included with SketchUp. In Blender, the file is converted into a file that can be read by ISA. Finally, in ISA the vegetation, buildings, signage and other details are added.

\section{Task 4: Scenario Validation}

Comparisons between driving speeds in real-life environments with driving speed in simulators are commonly used to validate driving simulation scenarios [13]. There must not be any significant differences for the scenarios to be validated.

Speed Spot Studies are conducted for the data collection of the speeds in real-life; the speeds are measured in specific locations where vehicles are driving at free flow. Then, several subjects run the base scenarios in the driving simulator and the information of their speeds is collected at the same locations where the Speed Spot Studies were performed. The two groups of speeds are compared to observe if there are significant differences between them. In case there is a significant difference, modifications must be made to the scenarios and new subjects must run the base scenario until the scenario can be validated.

\section{Task 5: Experimental Scenarios Development}

For the development of the experimental scenarios, the base scenario is used, and then the modifications needed are made to add the signage and pavement markings to be studied.

\section{Task 6: Data Collection}

To evaluate drivers' performance with the changes in signage, a subjects group, which can represent the real-world driving population is recruited. Each subject runs both the base and the experimental scenarios.

\section{Task 7: Statistical Analysis}

Statistical analysis is performed on the data collected. This analysis is used to evaluate if there are any significant differences in the behavior of the subjects while driving the scenarios of the school zones with the current signage and the scenarios with the new combinations of signs and pavement markings.

\section{Task 8: Conclusion and Recommendations.}

Conclusions are made about the behavior shown by drivers in each of the evaluated scenarios considering the results obtained in task 7. Correspondingly, recommendations are developed related to the combination of signage and pavement markings that can improve the safety around school zones.

\section{COUNTERMEASURES TO BE STUDIED}

Researchers have studied the influence of signage in drivers' behavior around school zones. In 2016 a study conducted in the state of Mississippi, United States, evaluated the effect of 
sign saturation in speed, and found that drivers implement a lower speed when driving in zones with high saturation [14].

For the studies that are being carried out it is expected to implement countermeasures that include signs with the current characteristics of colors, size and location as established in the MUTCD. The signage will be complemented with pavement markings that includes texts because surveys indicate that in Puerto Rico the text is very helpful for drives to identify school zones.

A study at a school zone in Australia, located after a signalized intersection, shows that, in comparison to using only the text, traffic signs that implement text with flashing lights convey the message and make drivers' significantly reduce their speed [15]. Also, in South Korea, the use of speed monitoring displays have proved to generate a significant reduction of vehicles speed in a long-term period [16]. These methods have shown to increase drivers' compliance and reduce speed in school zones, but they have not been implemented in Puerto Rico. Thus, they will be tested in the driver simulator with Puerto Rican drivers to observe if they generate the same results of drawing drivers attention and create a greater improvement in safety by reducing drivers speed.

\section{EXPECTED BENEFITS}

It is expected to develop and test a methodology that uses driving simulation to evaluate different aspects of school zones safety. Furthermore, this research will help to understand drivers' behavior in school zones and around them and to identify signage that contributes to the reduction of speeds used by drivers in and around school zones.

\section{ACKNOWLEDGMENTS}

This project is sponsored by the SAFER-SIM program. This support is greatly appreciated. The authors would like to express special thanks to Johnathan Ruiz, Bryan Ruiz, and Ivelisse Ramos, graduate research assistants, for their collaboration on the development of this research. The authors also express their thanks to Julio Valdés for helping with the initial editing of this work.

\section{REFERENCES}

OMS, "Informe sobre la situación mundial de la seguridad vial," p. 287,2009 .

Banco Interamericano de Desarrollo, "Nueva publicación del BID analiza experiencias exitosas en seguridad vial en América Latina y el Caribe," 2016. [Online]. Available: https://www.iadb.org/es/noticias/comunicados-de-prensa/201607-11/nueva-publicacion-bid-experiencias-exito-seguridadvial $\% 2 \mathrm{C} 11512$.html "Alarming Dangers in School Zones," pp. 1-20, 2016.

Comisión para la Seguridad en el Tránsito, "Estadísticas," 2018. [Online].

Available: http://comisionparalaseguridadeneltransito.com/stats/. [Accessed: 01-Mar-2018].

[6] Department of Transportation and Public Works, "Article 5.02 of Law Number 22, The vehicle and Traffic Law of Puerto Rico Approve in 2000, 2009 Edition.," 2000.

[7] AASHTO, Highway Safety Manual, 1st ed. Washington D.C., 2010.

[8] Federal Highway Administration, "FHWA Road Safety Audit Guidelines," 2006.

[9] Federal Highway Administration, "Manual on Uniform Traffic Control Devices for Streets and Highways," 2009.

[10] J. González Compre, "Mejoras en las Medidas Para la Seguridad de las Zonas Escolares en el Área Oeste de Puerto Rico," Universidad de Puerto Rico Recinto Universitario de Mayagüez, 2016.

[11] R. Garcia, K. Maldonado, and E. Molina, "Six School Zones Spot Speed Study in Three West-Municipalities of Puerto Rico," University of Puerto Rico-Mayaguez Campus, 2016.

[12] N. J. Garber and L. A. Hoel, Traffic and Highway Engineering, Fourth. 2010

[13] H. Klee, C. Bauer, E. Radwan, and H. Al-Deek, "Preliminary Validation of Driving Simulator Based on Forward Speed," Transp. Res. Rec. J. Transp. Res. Board, vol. 1689, pp. 33-39, 1999.

[14] L. Strawderman, M. M. Rahman, Y. Huang, and A. Nandi, "Driver behavior and accident frequency in school zones: Assessing the impact of sign saturation," Accid. Anal. Prev., vol. 82, pp. 118$125,2015$.

[15] B. Gregory, J. D. Irwin, I. J. Faulks, and E. Chekaluk, "Differential effects of traffic sign stimuli upon speeding in school zones following a traffic light interruption," Accid. Anal. Prev., vol. 86, pp. 114-120, 2016.

[16] L. Choulki, L. Sangsoo, C. Bongsoo, and O. Youngtae, "Effectiveness of Speed-Monitoring Displays in Speed Reduction in School Zones," Transp. Res. Rec. J. Transp. Res. Board, no. 1973, pp. 27-35, 2006. 